\title{
CARACTERIZACIÓN SOCIO-GEOGRÁFICA DE LOS ASENTAMIENTOS INFORMALES EN EL AGLOMERADO GRAN RESISTENCIA
}

\section{SOCIO-GEOGRAPHICAL CHARACTERIZATION OF INFORMAL SETTLEMENTS IN THE AGGLOMERATE GRAN RESISTENCIA}

\author{
Prof. Dr. Aníbal Marcelo Mignone \\ Profesor Titular. Cátedra Geografía Argentina \\ Auxiliar Docente. Geografía de América \\ Departamento de Geografía, UNNE \\ Centro de Geociencias Aplicadas, UNNE
}

Email: animarmig@hotmail.com

\section{RESUMEN:}

El aglomerado Gran Resistencia ha tenido diferentes modalidades de expansión urbana desde la segunda mitad del siglo XX y hasta la actualidad. Una de ellas, son los asentamientos informales, más conocidos como asentamientos espontáneos o irregulares, fenómeno generado mediante la ocupación ilegal de terrenos y que se ha transformado en una las principales formas de crecimiento del ejido urbano. Estos asentamientos informales, localizados mayoritariamente en la periferia del aglomerado, se destacan por una serie de falencias estructurales y sociales mientras que la población presenta déficit en la infraestructura de sus viviendas y dificultades de acceso a su propio terreno. Esta investigación, pretende realizar una caracterización socio-geográfica de los asentamientos informales surgidos en el aglomerado Gran Resistencia, desde la década de 1990 y hasta la actualidad.

\section{PALABRAS CLAVES}

Asentamientos informales; Gran Resistencia; características sociales.

\section{ABSTRACT}

The agglomerate Gran Resistencia has had various forms of urban expansion since the second half of the twentieth century until today. One of them, are better known as spontaneous informal settlements or slums, a phenomenon generated by the illegal occupation of land and has become a major form of growth of the urban area. These informal settlements, located mainly in the periphery of the agglomerate, are highlighted by a series of structural and social deficiencies while the population has the infrastructure deficit in their homes and difficulties of access to their own land. This research aims to conduct a sociogeographical characterization of informal settlements emerged in the agglomerate Gran Resistencia from the 1990s until today.

\section{KEY WORDS}

Informal settlements; Gran Resistencia; social characteristics. 


\section{Introducción}

Numerosas son las definiciones conceptuales acerca de los asentamientos informales; aunque primordialmente coinciden en mencionar que son asentamientos humanos colectivos, concentrados espacialmente en el interior de los ámbitos urbanos, que presentan características de ilegalidad e irregularidad en el acceso y ocupación de los terrenos, y con una población de bajos recursos económicos y en condiciones de pobreza. Se los conoce también como "asentamientos espontáneos", "asentamientos precarios", "barrios marginales"1, "barrios espontáneos", "barrios irregulares", "barrios precarios", "la ciudad ilegal", "villas espontáneas" o "villas periféricas". A sus habitantes, se los ha generalizado con el nombre de los "sin techo" o los "sin tierra", pero para los funcionarios suelen ser simplemente "intrusos" que ocupan ilegalmente los terrenos.

Visualmente significan la ocupación de una propiedad privada o de tierras públicas (calles, espacios verdes, áreas circundantes a lagunas); de terrenos municipales, provinciales o estatales (como zonas próximas a los ferrocarriles o áreas del ejército argentino); que no fueron adquiridos de manera legal y con la correspondiente escritura nominal2.

Según Agostinis (en Cozzi, s/f.), los asentamientos informales presentan características disímiles respecto a las villas de emergencia. Estas diferencias pueden apreciarse en el cuadro $N^{\circ} 1$ :

\begin{tabular}{|c|c|c|}
\hline & VILLA DE EMERGENCIA & ASENTAMIENTO \\
\hline $\begin{array}{l}\text { Contexto social en el } \\
\text { que surgen }\end{array}$ & $\begin{array}{l}\text { Período con posibilidades } \\
\text { relativas de: } \\
-\quad \text { ascenso social } \\
\text { - } \quad \text { nivel de salarios aceptable } \\
\text { - } \quad \text { aumento del nivel de empleo }\end{array}$ & $\begin{array}{l}\text { Período de crisis aguda: } \\
\text { - } \quad \text { fragmentación y descenso } \\
\text { social. } \\
\text { - } \quad \text { caída de salario } \\
\text { - } \quad \text { aumento del desempleo }\end{array}$ \\
\hline Movimientos migratorios & $\begin{array}{l}\text { Vinculada a movimientos } \\
\text { migratorios campo-ciudad. } \\
\text { Contingente con experiencia } \\
\text { predominantemente rural. }\end{array}$ & $\begin{array}{l}\text { Vinculada a migraciones internas } \\
\text { a lo urbano. } \\
\text { Contingentes con experiencia } \\
\text { predominantemente urbana, y } \\
\text { experiencia laboral en industria o } \\
\text { servicios. }\end{array}$ \\
\hline Tipo & $\begin{array}{l}\text { Predominantemente individual/ } \\
\text { familiar. } \\
\text { Crecimiento a través de sucesivas } \\
\text { incorporaciones basadas en redes } \\
\text { sociales/ familiares. }\end{array}$ & Estrategia colectiva. \\
\hline Org & $\begin{array}{l}\text { No la requieren al principio. } \\
\text { Surge para incorporar mejoras o } \\
\text { evitar desalojos. }\end{array}$ & $\begin{array}{l}\text { Requiere la organización previa a } \\
\text { la toma y en muchos casos de } \\
\text { apoyo externo. } \\
\text { ĺdem para formar y consolidar el } \\
\text { asentamiento. }\end{array}$ \\
\hline Control del espacio & $\begin{array}{l}\text { Inicialmente individual. } \\
\text { Posteriormente surge la } \\
\text { necesidad de acciones colectivas: } \\
\text { control de pasillos, suministro de } \\
\text { agua, electricidad, etc. } \\
\text { No respeta la trama urbana. } \\
\end{array}$ & $\begin{array}{l}\text { Comunitario desde el principio por } \\
\text { el modo de apropiación del } \\
\text { terreno; amanzanamientos, } \\
\text { subdivisión en lotes, construcción } \\
\text { de calles y espacios comunes. } \\
\text { Respeta la trama urbana. }\end{array}$ \\
\hline $\begin{array}{l}\text { En cuanto a } r \text { la } \\
\text { posesión/propiedad } \\
\text { la tierra }\end{array}$ & $\begin{array}{l}\text { Ocupación ilegal, privilegia la } \\
\text { posesión y el usufructo del terreno } \\
\text { que ocupa. }\end{array}$ & $\begin{array}{l}\text { Ocupación ilegal con vocación de } \\
\text { entrar a la legalidad. Buscar } \\
\text { activamente la propiedad de la } \\
\text { tierra, ejerciendo presión. }\end{array}$ \\
\hline Relación con el estado & $\begin{array}{l}\begin{array}{l}\text { Demanda al estado, } \\
\text { soluciones } \\
\text { definitivas. }\end{array} \\
\text { tipo }\end{array}$ & $\begin{array}{l}\text { No espera soluciones definitivas } \\
\text { desde el Estado; busca su } \\
\text { mediación. }\end{array}$ \\
\hline
\end{tabular}

Cuadro № 1: Cuadro comparativo: villa de emergencias y asentamientos informales

Publicado en formato digital: Prof. Dr. Aníbal Marcelo Mignone. CARACTERIZACIÓN SOCIO-GEOGRÁFICA DE LOS ASENTAMIENTOS INFORMALES EN EL AGLOMERADO GRAN RESISTENCIA. Revista Geográfica Digital. IGUNNE. Facultad de Humanidades. UNNE. Año 12. No 24. Julio - Diciembre 2015. ISSN 1668-5180 Resistencia, Chaco.

En: http://hum.unne.edu.ar/revistas/geoweb/default.htm 


\section{La localización espacial de los asentamientos}

Existe una lógica similar en cuanto a la localización de los asentamientos informales en el aglomerado Gran Resistencia. La concentración de estos barrios marginales aparece en los terrenos bajos e inundables próximos al riacho Barranqueras. La cercanía al río se asocia con actividades de subsistencia como la pesca, el empleo de agua para el lavado de la ropa o el propio aseo personal (Mignone, 2002, 2004, 2008). Asimismo, se encuentran asentados a la vera de los ríos, arroyos y lagunas que se hallan en el interior de la ciudad: por ejemplo los núcleos informales próximos al río Negro y lagunas importantes del norte de la ciudad de Resistencia.

Por otra parte, aparecen en aquellos lugares donde no ha llegado la infraestructura de los servicios, precisamente en terrenos por el momento no urbanizados y de bajo costo. O de manera opuesta, se destacan por su proximidad a los complejos habitacionales o barrios planificados, o sectores con altos ingresos. Según las encuestas realizadas en los asentamientos informales de la ciudad de Resistencia3 los habitantes pueden desarrollar diferentes actividades como el servicio doméstico, albañilería o el comercio ambulante, entre otros. Asimismo, la cercanía de los barrios, constituyen fuentes cercanas de provisión de agua, servicios básicos y posibilidad laboral por medio de las "changas". Por otra parte, la generación de los barrios planificados va dejando entre los mismos, intersticios de terrenos fiscales y privados que son (o fueron) objeto de asentamientos marginales.

La instalación está también en relación con los terrenos y sus condiciones ambientales, además de considerar la proximidad a las vías de circulación. Con respecto a esto último, se debe tener en cuenta la preferencia por las mejores condiciones de accesibilidad, en términos de menor costo-distancia, desde la periferia hacia el centro (Marotte, 2000:363). Esto se puede ejemplificar con los núcleos espontáneos que se localizan en las proximidades de las principales avenidas de la ciudad de Resistencia.

En otras situaciones, la instalación obedece a razones políticas. La realidad de los intrusos se ve agravada por la legitimación que ejercen los dirigentes políticos cuando promueven las ocupaciones o simplemente no establecen normas claras para la organización de la ciudad. A la hora del debate, la clase dirigente es la más criticada por los propietarios, quienes los acusan de considerar los terrenos privados como instrumentos electoralistas. Ocurre que algunos representantes políticos incitan a la ocupación de los terrenos en épocas de elecciones, como medio para la obtención de votos y se torna partidariamente muy difícil tomar medidas antipopulares y no solidarias.

Como ejemplo de la ciudad de Resistencia, se puede citar la ocupación de los terrenos de La Rubita (pertenecientes al ejército) con el aval de ciertos funcionarios políticos, que tuvo lugar en marzo de 1997. Fue una ocupación masiva de tierras (con más de 300 familias), duró una semana y sus habitantes fueron desalojados por la Gendarmería Nacional, para posteriormente ser relocalizados en otro sector de la ciudad4.

También está presente la especulación de las compañías inmobiliarias, que provocan la ocupación a efectos de promover la posibilidad de expropiación de los terrenos (Norte, 26/11/1994:13). Ciertamente, con la toma de tierras, el valor del terreno ocupado se incrementa, significando notorias ganancias para las compañías5. Por su parte, los operadores inmobiliarios coinciden en que la solución no pasa por generar una nueva ley de Tierras, sino por flexibilizar el Código de Urbanismo de la propia ciudad, que impide que la gente de escasos recursos tenga acceso a un lote económico. Los operadores establecen que con las expropiaciones se genera "todo un negocio", porque consideran que es la mejor solución para el propietario del terreno, que no podía subdividirlo por las exigencias municipales. También consideran que se instiga a la usurpación para forzar la expropiación, y entonces el propietario usurpado termina cobrando en efectivo, todo el dinero (Norte, 08/09/2002:4).

Por otra parte, aparece la especulación del loteo que explota la necesidad e ignorancia de esta población, a través de transacciones irregulares (Comisión de Tierras Fiscales Nacionales, 1994). Ocurre que existen moradores que ven esta forma de ocupación con un fin lucrativo, ocupan un terreno, construyen una vivienda precaria y ante las dificultades para acceder a los títulos de

Publicado en formato digital: Prof. Dr. Aníbal Marcelo Mignone. CARACTERIZACIÓN SOCIO-GEOGRÁFICA DE LOS ASENTAMIENTOS INFORMALES EN EL AGLOMERADO GRAN RESISTENCIA. Revista Geográfica Digital. IGUNNE. Facultad de Humanidades. UNNE. Año 12. № 24. Julio - Diciembre 2015. ISSN 1668-5180 Resistencia, Chaco.

En: http://hum.unne.edu.ar/revistas/geoweb/default.htm 
propiedad, optan por venderlo luego a precios elevados (Imagen $N^{0} 1$ ). Posteriormente, esos grupos se mueven a otro lugar para continuar con el ciclo de especulación6.

Asimismo, la ocupación de los espacios periféricos que se encontraban suburbanizados o directamente sin urbanizar, van a generar la especulación inmobiliaria por parte de los nuevos moradores localizados en estos terrenos. Justamente, en las últimas dos décadas, han aumentado el número de asentamientos informales en terrenos privados, generando verdaderos conflictos entre los propietarios legales, los nuevos ocupantes y los organismos estatales.

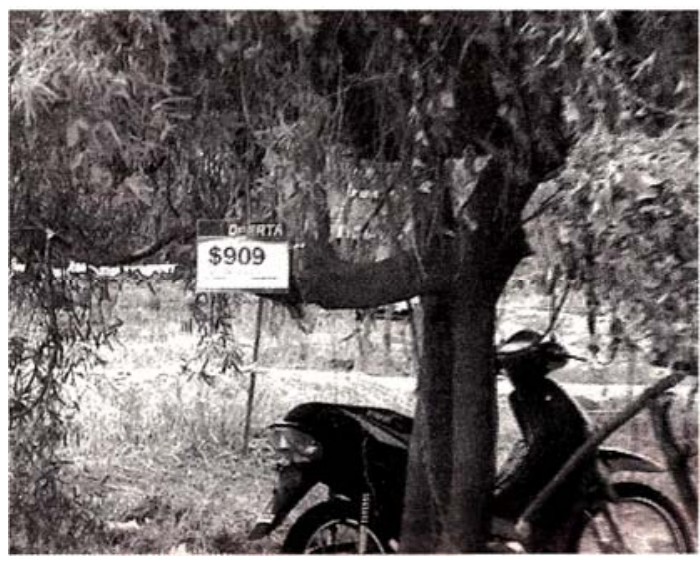

Imagen $N^{\circ}$ 1: Venta de terrenos en asentamientos informales. Ciudad de Resistencia Fuente: Norte. 19/01/2008:3

A todo esto, se suma el marco de ilegalidad urbana, en gran medida, por efecto del propio orden jurídico. La ley se constituye en un factor importante de la ampliación de la ilegalidad en las ciudades latinoamericanas, sobre todo porque, de manera fuerte, dominante y hegemónica, todavía prevalece una visión conservadora, individualista, civilista y patrimonialista de los derechos individuales de propiedad. Esta visión sigue orientando gran parte de la acción de los tribunales e incluso de la opinión pública (Fernandes, 2008:16).

\section{Modalidad de ocupación de los terrenos}

La modalidad de ocupación, presenta notorias diferencias en las últimas décadas. Antes de 1990, los asentamientos se caracterizaban por contar con grupos familiares instalados en forma individual, paulatina y en un tiempo relativamente largo. Su desorganización era otra característica; los terrenos se ocupaban en forma irregular, sin calles trazadas o con senderos de acceso interrumpidos por alguna vivienda.

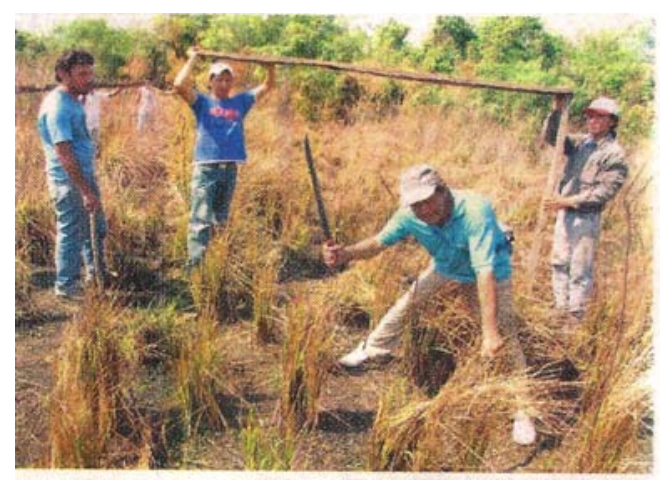

Fuente: Norte. 18/03/2008:44

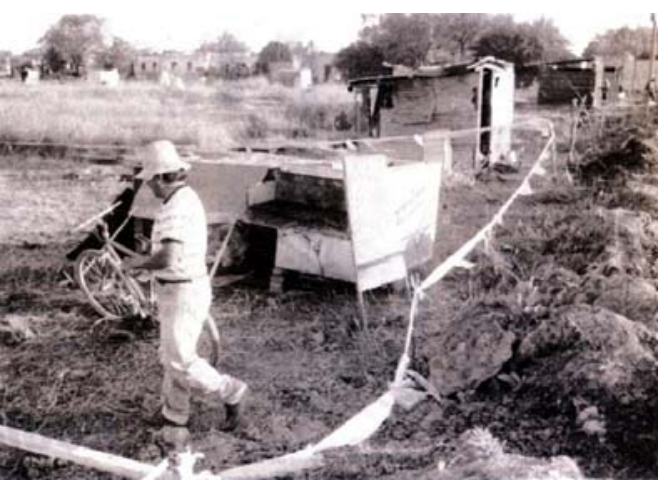

Fuente: Norte. 07/08/2002:7

Imagen № 2: Ocupación de terrenos: proceso de limpieza y medición. Ciudad de Resistencia

En los asentamientos de la última década, la forma de ocupación presentó cambios sustanciales. Al momento de la instalación se efectúa la subdivisión de las parcelas, buscando un

Publicado en formato digital: Prof. Dr. Aníbal Marcelo Mignone. CARACTERIZACIÓN SOCIO-GEOGRÁFICA DE LOS ASENTAMIENTOS INFORMALES EN EL AGLOMERADO GRAN RESISTENCIA. Revista Geográfica Digital. IGUNNE. Facultad de Humanidades. UNNE. Año 12. No 24. Julio - Diciembre 2015. ISSN 1668-5180 Resistencia, Chaco.

En: http://hum.unne.edu.ar/revistas/geoweb/default.htm 
trazado regular y dejando los espacios para la apertura de las calles públicas o semi-públicas que las comuniquen (Imagen $\mathrm{N}^{\circ}$ 2). Se realizan mediciones de los terrenos (tratando de respetar las medidas establecidas de acuerdo a la norma municipal) que aunque imprecisas, logran mantener cierto orden en la distribución parcelaria. Asimismo, la organización de los ocupantes sirve para afrontar e impedir el desalojo impulsado por los propietarios de los terrenos, obtener beneficios para el asentamiento (chapas, agua, etc.) y lograr la ley de expropiación del terreno ocupado y con ello la posterior regularización dominial y consolidación del asentamiento; También en muchos casos se usa para demandar asistencia alimentaria y/o puestos de empleos en los programas sociales (cf. Magnano, 2005).

Esta estrategia de apropiación es llevada a cabo por grupos que tienen mayor organización previa, formados con ese fin, y las tierras que son ocupadas generalmente son de mayor valor. Es por eso que en algunos casos las tomas resultaron conflictivas. Sin embargo, estos grupos han practicado diferentes formas de articulación con el poder político y organizaciones civiles de asistencia que los han "ayudado" en la ocupación (Barreto y Sánchez, 2000). Además, a diferencia de las ocupaciones pasadas, se realiza una toma masiva de los terrenos, con numerosas familias (inicialmente en un número inferior a 40) que se instalan y construyen casillas de chapas de cartón o material de desecho, mezclado con maderas o troncos.

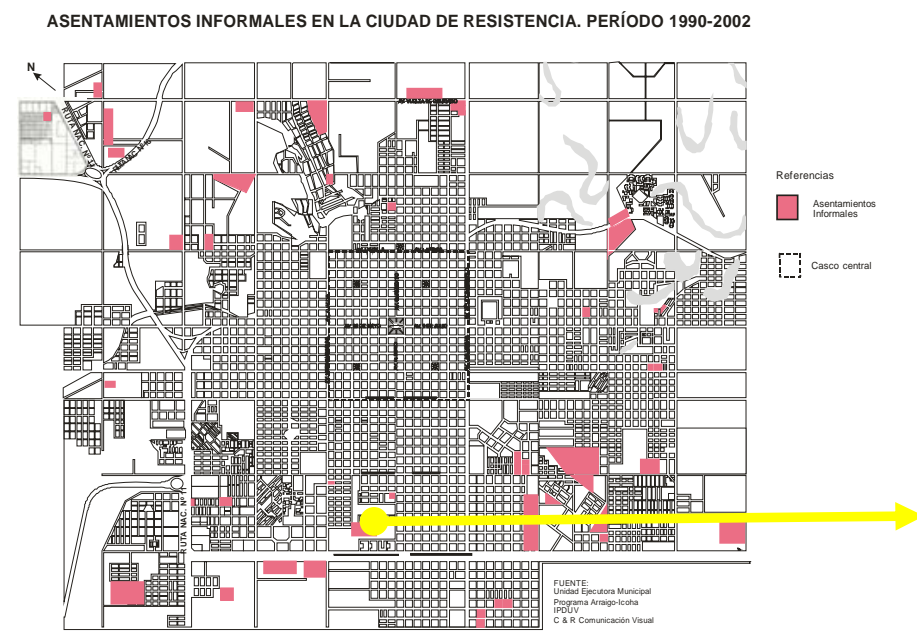

Fuente: Unidad Ejecutora de la Municipalidad de Resistencia; Programa Arraigo-Icoha; IPDUV; C \& R Comunicación Visual

\section{Imagen No 3: Asentamiento "2 de Abril". Ciudad de Resistencia}

Muchas de las ocupaciones provocan conflictos con los propietarios del terreno, que pretenden la expulsión de los asentados. Sin embargo resulta imposible retirarlos del lugar ocupado. Como ejemplo se puede mencionar a los asentados a la vera de los campos del Golf Club en la ciudad de Resistencia (a partir de 1992), cuando personal de la municipalidad intentó retirar a la población que ocupaban terrenos municipales, pero los habitantes lograron mantenerse hasta la actualidad. Asimismo, la imagen № 3 muestra el asentamiento "2 de Abril", instalado a principios de diciembre del año 2000. En este caso, la ocupación se realizó sobre terrenos fiscales y privados. En el primero de los casos, los ocupantes tuvieron el aval municipal para la ocupación, mientras que las familias localizadas en terrenos privados, han tenido una situación más conflictiva desde el marco jurídico y dominial.

Ocurre que los individuos estudian el lugar a ocupar, informándose sobre el propietario y la condición impositiva que presenta el mismo. Posteriormente se organizan los grupos que ocupan las parcelas. El esquema presentado (Figura $N^{\circ} 1$ ) sintetiza las modalidades que provocan la existencia e incremento en el número de asentamientos informales.

Publicado en formato digital: Prof. Dr. Aníbal Marcelo Mignone. CARACTERIZACIÓN SOCIO-GEOGRÁFICA DE LOS ASENTAMIENTOS INFORMALES EN EL AGLOMERADO GRAN RESISTENCIA. Revista Geográfica Digital. IGUNNE. Facultad de Humanidades. UNNE. Año 12. № 24. Julio - Diciembre 2015. ISSN 1668-5180 Resistencia, Chaco.

En: http://hum.unne.edu.ar/revistas/geoweb/default.htm 
Determinar una cifra aproximada de la población localizada en asentamientos informales es muy difícil, debido a las condiciones de movilidad que tiene la población localizada en estos lugares. Como ejemplo, citamos que la UEM (Unidad Ejecutora Municipal de Resistencia), entre 1990/99 estimaba que 1.000 era el número aproximado de familias instaladas en los asentamientos de la capital chaqueña. Si se tiene en cuenta que consideraba cada familia con cinco integrantes, se hacía un total de 5.000 habitantes como valor mínimo. Complementariamente la Facultad de Arquitectura y Urbanismo de la UNNE, que había trabajado por convenio (en ese entonces) con el plan Arraigo7ICoHa, estimaba para el período 1990/96 que el número aproximado de viviendas asentadas era de 1.830. Tomando seis integrantes por cada familia, hacían un total cercano a 11.000 personas.

En 1995, un artículo periodístico mencionaba la existencia de 13.000 hogares intrusos, de los cuales 5.000 se concentraban en terrenos municipales, 7.000 en propiedades privadas y 800 en tierras públicas (Norte, 19/03/1995:3). Otro informe, estimaba un total de 10.132 familias involucradas en la problemática (Norte, 23/04/01:4). Estas diferencias son producto de las dificultades que existían (y existen) al momento de relevar la información estadística de la población, porque se trata de un proceso de ocupación rápida, con importantes grupos familiares instalados en un lugar en pocos días y porque los propios habitantes generan un movimiento interno al desplazarse de un asentamiento a otro, ante la inseguridad existente para la adjudicación de los terrenos. Por ello aparece la especulación del loteo, que explota la necesidad e ignorancia de esta población, a través de transacciones irregulares (Comisión de Tierras Fiscales Nacionales, 1994). Ocurre que existen moradores que ven esta forma de ocupación con un fin lucrativo, ocupan un terreno, construyen una vivienda precaria y ante las dificultades para acceder a los títulos de propiedad, optan por venderlo luego a precios elevados. Posteriormente, esos grupos se mueven a otro lugar para continuar con el ciclo de especulación8.
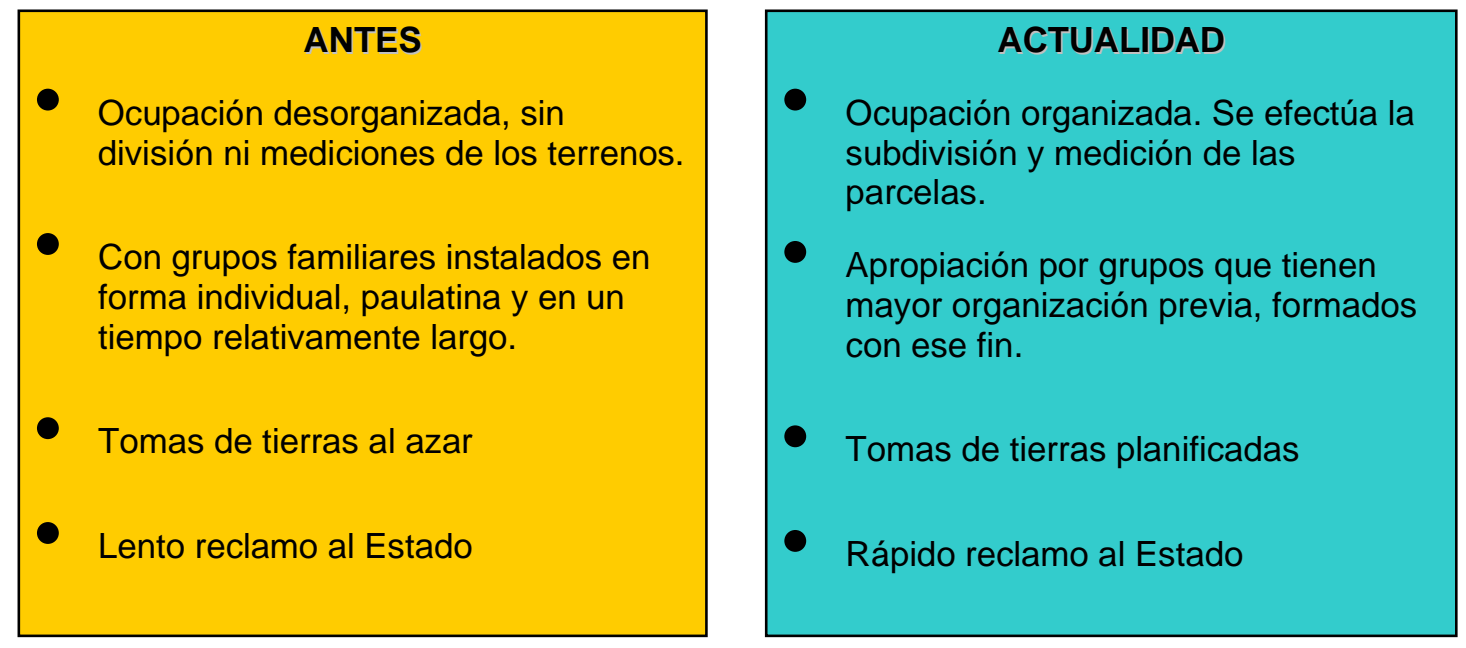

Figura $N^{\circ}$ 1: Esquema comparativo de las modalidades de ocupación de los asentamientos informales. Fuente: Elaboración propia en base a Mignone, 2004, 2005, 2008

Por lo tanto, para los diferentes organismos dedicados a solucionar la pobreza o a mejorar la calidad de vida de estos habitantes, les resulta difícil contar con un número aproximado de habitantes. Sin embargo, mediante los programas sociales y de planificación territorial que fueron surgiendo con posteridad al año 2000, y especialmente durante el último decenio, se ha tratado de tener una estadística certera de estos conjuntos de población.

\section{La vivienda y la provisión de los servicios}

Presentan condiciones deficitarias de todo orden. Inicialmente muchas viviendas son construcciones de materiales precarios combinando burdamente chapa, cartón, madera, entre otros. Básicamente las familias cercan sus lotes otorgándoles formas irregulares y generalmente de medidas disímiles, limpian las malezas o cavan pozos para los troncos de palma que se utilizan como

Publicado en formato digital: Prof. Dr. Aníbal Marcelo Mignone. CARACTERIZACIÓN SOCIO-GEOGRÁFICA DE LOS ASENTAMIENTOS INFORMALES EN EL AGLOMERADO GRAN RESISTENCIA. Revista Geográfica Digital. IGUNNE. Facultad de Humanidades. UNNE. Año 12. № 24. Julio - Diciembre 2015. ISSN 1668-5180 Resistencia, Chaco.

En: http://hum.unne.edu.ar/revistas/geoweb/default.htm 
estructura. En el fondo del lote se construye la letrina con pozo ciego o enganchado con un pozo existente. Incluso el trazado de estos barrios es caótico, debido a su condición de espontaneidad, lo que dificulta el acceso de recolectores de residuos, bomberos o servicios de emergencias en casos de urgencia (Norte, 26/11/94:13).

Otros pobladores sólo tienen la posibilidad de vivir en carpas (Imagen № 4) y algunos logran consolidar su vivienda con el correr del tiempo, lo que hace más dificultoso su posterior traslado o erradicación.

Asimismo, la provisión de servicios básicos no suele acompañar la expansión acelerada de la periferia de las ciudades. Una necesidad vital como el agua presenta dificultades en su servicio, desde la colocación de cañerías domiciliarias hasta la canilla pública para el asentamiento, o incluso el aprovisionamiento con tanques municipales. La provisión de agua potable se realiza por medio de canillas públicas (Imagen № 5), que en muchos casos, la población dispone cada 100 o 200 metros; o por otra parte, no tienen provisión de agua por cañerías, entonces la población concurre a los complejos habitacionales para obtenerla ${ }^{167}$.

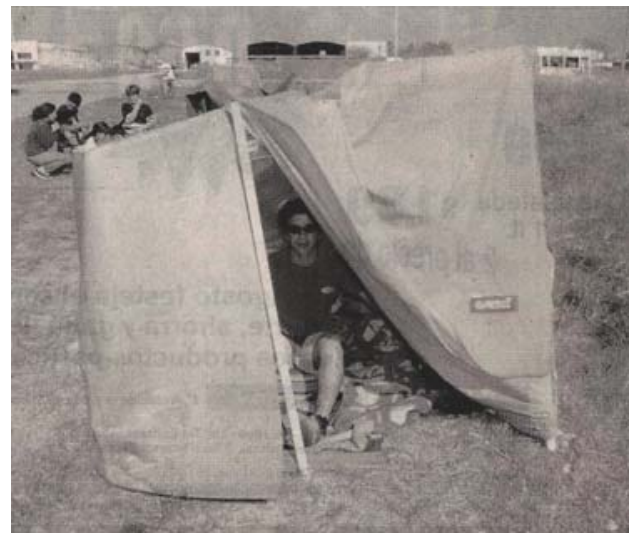

Fuente: Norte. 08/08/2002:4

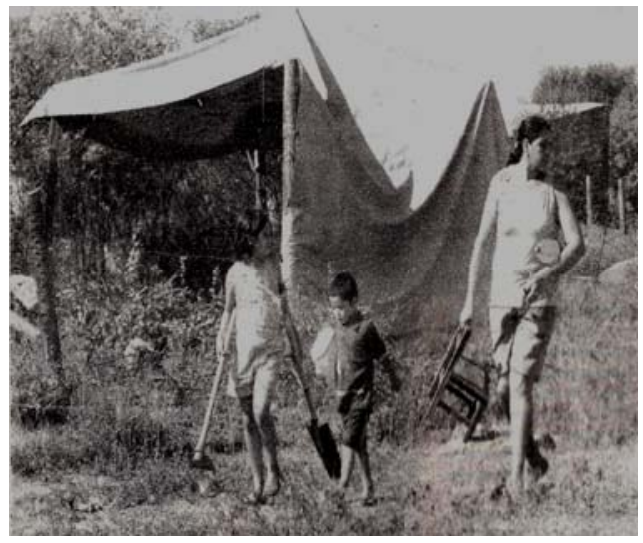

Fuente: Norte. 21/05/2009:7

Imagen № 4: Ocupaciones de terrenos: instalaciones con carpas. Ciudad de Resistencia

Lo mismo se puede decir del servicio de electricidad, ya que las viviendas presentan mayoritariamente conexiones en forma "clandestina o enganchada", sin ningún tipo de precaución (sin descarga de tierra, con cables que cuelgan de palos y ramas) ni registro.

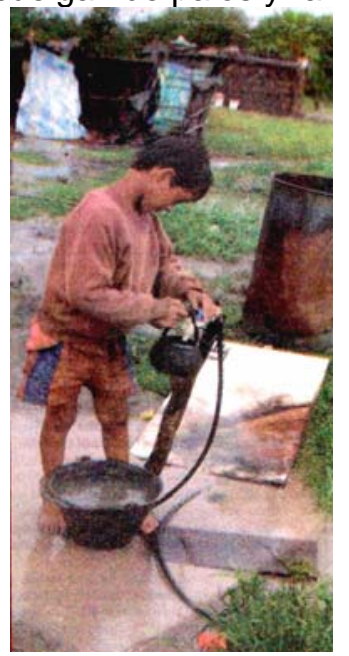

Imagen №5: Provisión de agua potable mediante canillas públicas. Ciudad de Resistencia Fuente: Norte. 15/11/2009:9.

${ }^{167}$ Esta situación observada en 2003, sigue hasta el momento de redactar esta tesis doctoral.

Publicado en formato digital: Prof. Dr. Aníbal Marcelo Mignone. CARACTERIZACIÓN SOCIO-GEOGRÁFICA DE LOS ASENTAMIENTOS INFORMALES EN EL AGLOMERADO GRAN RESISTENCIA. Revista Geográfica Digital. IGUNNE. Facultad de Humanidades. UNNE. Año 12. No 24. Julio - Diciembre 2015. ISSN 1668-5180 Resistencia, Chaco.

En: http://hum.unne.edu.ar/revistas/geoweb/default.htm 
El alumbrado público es otro servicio que la población no tiene, lo cual en horarios nocturnos, acrecienta la inseguridad y dificulta el recorrido por las calles de tierra. A esto, se suman los problemas que generan la falta de cloacas o el asfalto; la ausencia de este último provoca importantes dificultades para el tránsito de los propios vecinos, especialmente en los períodos lluviosos y húmedos.

La provisión de los servicios en el aglomerado es muy lenta, de tal forma que el casco central y los barrios planificados próximos al mismo, cuentan con los cuatro servicios básicos, pero los núcleos residentes en asentamientos informales, coinciden con lugares donde solamente tienen agua potable o electricidad.

De cualquiera manera, también se debe reconocer que existe una evolución en la condición edilicia, sanitaria y ambiental del espacio dónde se localizan los asentamientos. Como ejemplo, se puede observar como se ha modificado el paisaje urbano en el asentamiento "Belgrano" de la ciudad de Resistencia. La fotografía del año 2002 (Imagen No 6), dónde las carencias están a la vista, contrasta ocho años después con el alumbrado público, viviendas de materiales (incluso de dos pisos) con paredes perimetrales, cunetas, y arbolado público. No obstante, de diferentes comentarios obtenidos por la población residente en los asentamientos informales, la celeridad para el mejoramiento de los barrios depende muchas veces del clientelismo político, de la capacidad de gestión de los dirigentes barriales y de los diferentes mecanismos utilizados por la población para generar respuestas por parte de la dirigencia política.
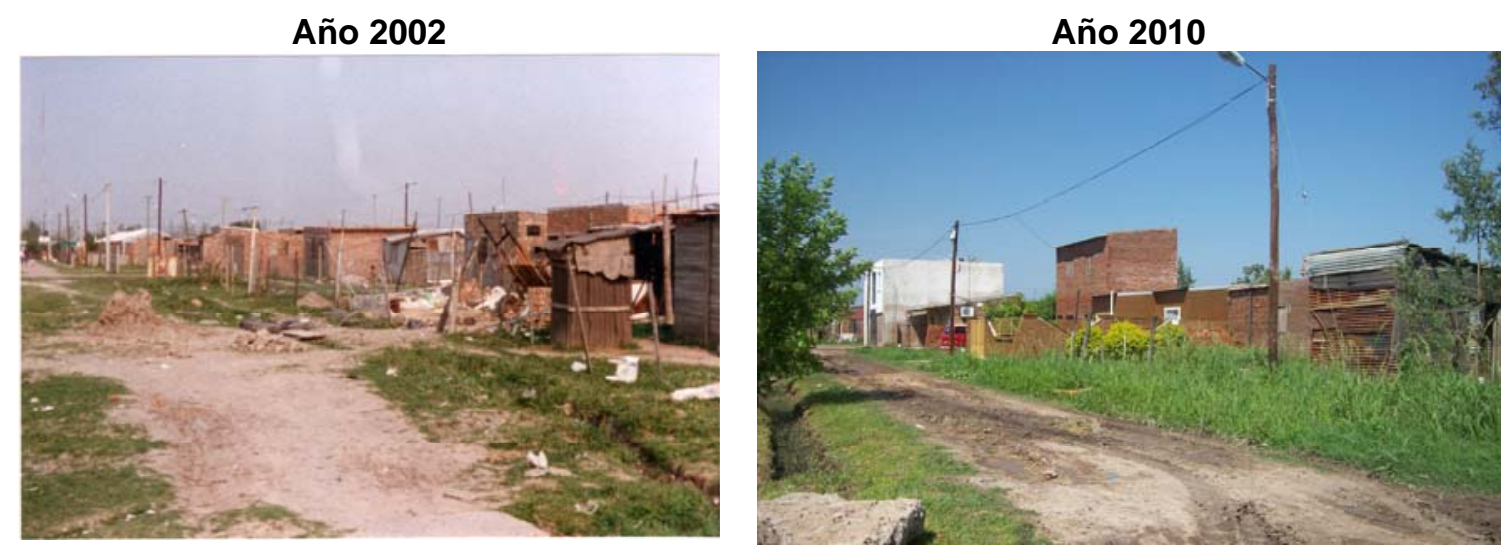

Fuente: Mignone, 2002 y 2010

Imagen № 6: Evolución edilicia en el asentamiento "Belgrano". Ciudad de Resistencia

\section{Metodología para el saneamiento parcelario y social}

De acuerdo con Fernández Wagner (citado por Bettatis 2009:93), han existido dos importantes modalidades en las políticas de intervención habitacional en los asentamientos informales de nuestro país: una de ellas fueron las viviendas "llave en mano" y un segundo tipo de intervenciones teñidas por las modificaciones en las concepciones internacionales acerca de las urbanizaciones informales, que se orientan a la mejora de los asentamientos, la radicación, la apertura de la participación, etc. El cuadro comparativo № 2 sintetiza las características señaladas.

Lo que ocurrió en la práctica ha sido una articulación y superposición de las distintas políticas de regularización dominial. De esta manera, numerosas han sido las actividades llevadas a cabo a fin de solucionar las condiciones de los asentamientos periféricos informales en la capital chaqueña.

Si el asentamiento se establece en terrenos municipales, la ocupación es permitida, pero comienza todo un proceso para regularizar la situación de los habitantes. Dentro de las estrategias más elementales están las de "consolidación", que consisten en mantener el asentamiento en su

Publicado en formato digital: Prof. Dr. Aníbal Marcelo Mignone. CARACTERIZACIÓN SOCIO-GEOGRÁFICA DE LOS ASENTAMIENTOS INFORMALES EN EL AGLOMERADO GRAN RESISTENCIA. Revista Geográfica Digital. IGUNNE. Facultad de Humanidades. UNNE. Año 12. № 24. Julio - Diciembre 2015. ISSN 1668-5180 Resistencia, Chaco.

En: http://hum.unne.edu.ar/revistas/geoweb/default.htm 
lugar de origen, integrándolo a la trama urbana. Se interviene en la regularización dominial y se producen mejoras sustanciales sobre la situación de necesidad habitacional.

La regularización dominial se lleva a cabo realizando el relevamiento físico de los terrenos, se elabora una propuesta de subdivisión y se realiza una asamblea con los ocupantes del asentamiento para llegar a un consenso. Luego de logrado el mismo, se ejecutan los planos de mensura y posteriormente se aprueba la resolución para librar la venta a los actuales ocupantes. Las adjudicaciones se realizan mediante planes de pagos o créditos, cuya financiación se realiza a precios bajos y a largo plazo ante la precaria situación económica que presenta gran parte de la población asentada9. A pesar del tiempo que puede demandar el pago, la financiación es aceptada por los habitantes a sabiendas que al saldar la deuda tendrán su título de propiedad. Otros pobladores critican este accionar porque consideran que se necesita tener una estabilidad laboral para hacer frente a esta política crediticia.

\begin{tabular}{|l|l|l|}
\hline Tipo de intervención & \multicolumn{1}{|c|}{ Políticas "Ilave en mano" } & \multicolumn{1}{|c|}{ Políticas "alternativas" } \\
irradicación de asentamientos & $\begin{array}{l}\text { Radicación de asentamientos } \\
\text { irregulares. }\end{array}$ \\
\hline Tipo de producto & $\begin{array}{l}\text { Construcción de conjunto } \\
\text { habitacional sobre terreno libre. }\end{array}$ & $\begin{array}{l}\text { Construcción de baja y media } \\
\text { complejidad (de baja } \\
\text { productividad). }\end{array}$ \\
\hline Financiamiento & $\begin{array}{l}\text { Fondos públicos, con muy bajo } \\
\text { o sin recupero (o recuperación). }\end{array}$ & $\begin{array}{l}\text { Fondos públicos u otras } \\
\text { fuentes, con recupero parcial o } \\
\text { total de inversión. }\end{array}$ \\
\hline $\begin{array}{l}\text { Decisión y } \\
\text { planificación }\end{array}$ & $\begin{array}{l}\text { Realizada por el Estado en } \\
\text { forma centralizada. }\end{array}$ & $\begin{array}{l}\text { Centralizada, con distintos } \\
\text { grados de participación de la } \\
\text { población. }\end{array}$ \\
\hline Construcción & $\begin{array}{l}\text { Grandes empresas por licitación } \\
\text { pública. }\end{array}$ & $\begin{array}{l}\text { Pequeñas empresas locales, } \\
\text { cooperativas, o los usuarios } \\
\text { organizados. }\end{array}$ \\
\hline Asignación social & $\begin{array}{l}\text { Listado de población } \\
\text { destinataria ordenado según } \\
\text { criterios de prioridad. }\end{array}$ & $\begin{array}{l}\text { Pre-acordada/proyecto gestado } \\
\text { en respuesta a una demanda } \\
\text { específica. }\end{array}$ \\
\hline Usuario & $\begin{array}{l}\text { Receptor pasivo, no participa en } \\
\text { la toma de decisiones. }\end{array}$ & $\begin{array}{l}\text { Receptor activo, con diferentes } \\
\text { grados de implicación en el } \\
\text { proceso. }\end{array}$ \\
\hline
\end{tabular}

Fuente: Fernández Wagner (inédito, citado por Bettatis 2009:93)

Cuadro $N^{\circ} 2$ : Modalidades de políticas de intervención habitacional

Por otra parte, distinta resolución se alcanza a través de la entrega del lote con una vivienda por autoconstrucción: la mano de obra de familia adjudicataria permite levantar el techo. Los vecinos desocupados son absorbidos en la construcción de las edificaciones y son capacitados en la organización y manejo de grupos de trabajo.

La "reubicación" del asentamiento se produce cuando éste no puede ser consolidado debido usualmente al riesgo ambiental que corre o por dificultad en la gestión del traspaso del dominio de las tierras a sus ocupantes, si se encuentran ocupando zonas de calles, lugares destinados a plazas, salud o educación. Indudablemente que para la ejecución de los proyectos, se deben realizar las tramitaciones pertinentes con el consiguiente tiempo y dinero que demandan.

La situación se vuelve más conflictiva si el asentamiento ocurre en terrenos de dominio privado. Se debe llegar a un acuerdo con los propietarios de los inmuebles ocupados, que no siempre aceptan el asentamiento y buscan la expulsión de sus moradores10. En ciertos casos se logra la cesión del terreno a cambio de compensación de deudas o crédito fiscal, o "por acción directa de los ocupantes que acrediten una posesión pacífica e ininterrumpida durante un plazo mínimo de 20 años

Publicado en formato digital: Prof. Dr. Aníbal Marcelo Mignone. CARACTERIZACIÓN SOCIO-GEOGRÁFICA DE LOS ASENTAMIENTOS INFORMALES EN EL AGLOMERADO GRAN RESISTENCIA. Revista Geográfica Digital. IGUNNE. Facultad de Humanidades. UNNE. Año 12. No 24. Julio - Diciembre 2015. ISSN 1668-5180 Resistencia, Chaco.

En: http://hum.unne.edu.ar/revistas/geoweb/default.htm 
a través de la realización de juicios de usurpación" (Comisión de Tierras Fiscales Nacionales, 1994). Esta acción se dificulta en los asentamientos más recientes, por el tiempo que requiere el cumplimiento de la norma.

Otra solución, por parte del Estado, consiste en la sanción de leyes que declaren de utilidad pública y sujetos a expropiación los inmuebles ocupados, permitiendo la regularización del dominio para las familias que los habitan. El problema se produce porque por cada asentamiento es necesario realizar la expropiación, y es el estado provincial quién debe asumir los gastos que demande el pago al dueño del terreno expropiado, con sumas que el estado no siempre puede disponer por sí solo. Por ello, muchas veces el gobierno debe vetar las leyes de expropiación, ante la situación de las finanzas públicas de la provincia. Existen críticas por parte de los propietarios de los terrenos ocupados, quienes se quejan porque nunca logran cobrar los que se les paga, convalidándose la usurpación y generando situaciones conflictivas. Muchas leyes de expropiación no son pagadas por el gobierno y la vigencia de la misma caduca a los años de sancionada. Esto también produce incertidumbre en los pobladores de los barrios expropiados11. Por otra parte, al momento de brindar las respuestas a estos conjuntos, tienden a superponerse el accionar de varios organismos públicos, lo que demanda una duplicación y hasta triplicación de gastos de funcionamiento que muchas veces terminan en resultados poco satisfactorios para la población (cf. Magnano, 2005).

La política de tierras también está sujeta a la coyuntura política. Un caso representativo fue el barrio 10 de Mayo de la ciudad de Resistencia, donde en el lapso de cuatro meses se compraron los terrenos, porque se transitaba por un período electoral. Entonces, estos grupos sociales cuentan con mayores posibilidades de saneamiento ambiental, si saben alcanzar distintos resortes estatales. Si existe un rédito político, entonces el grupo social se verá atendido (Barrios, 1999). El esquema de la figura $\mathrm{N}^{\circ} 2$, sintetiza lo anteriormente mencionado.

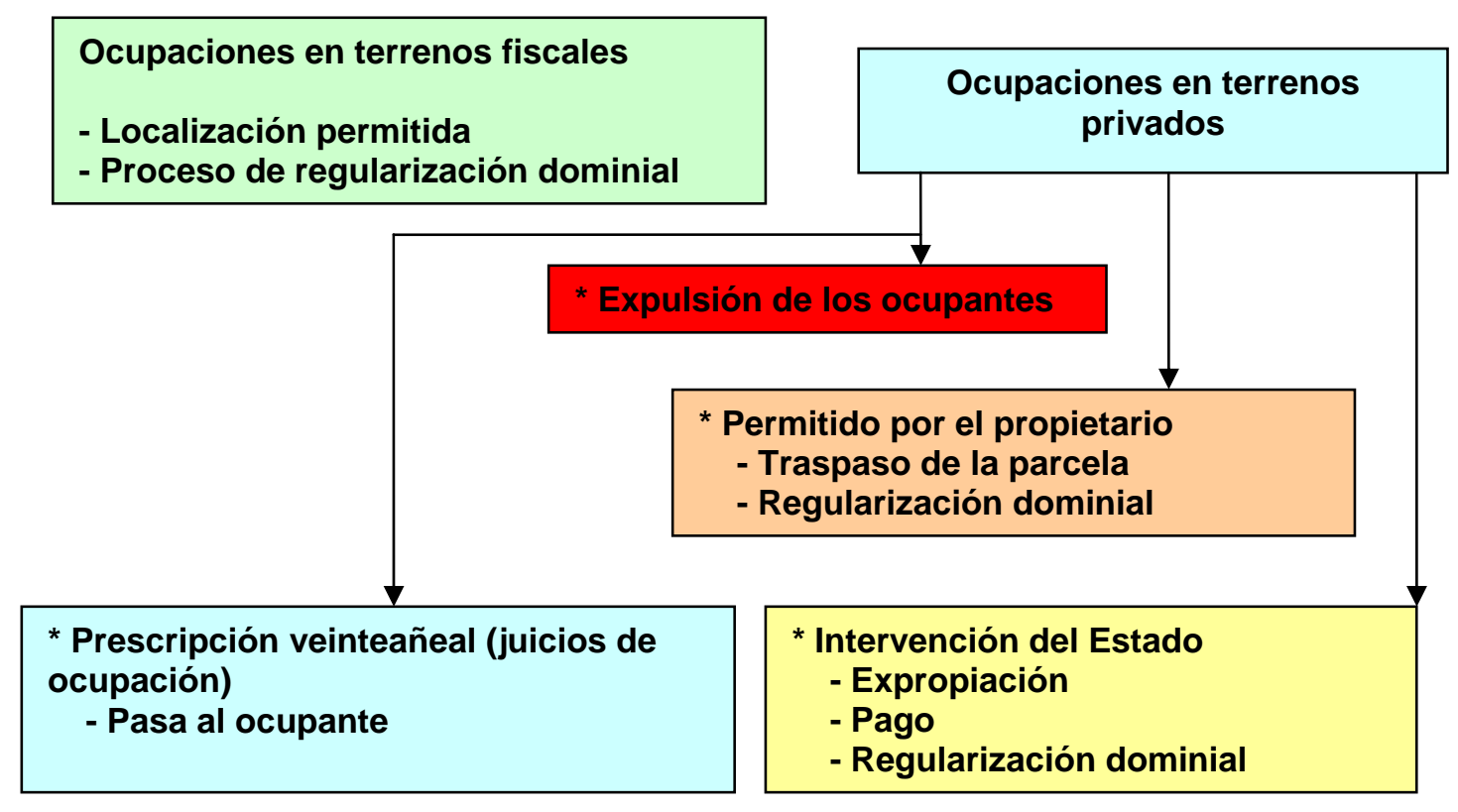

Fuente: Elaboración propia

Figura $N^{\circ} 2$ : Modalidades de regularización dominial en asentamientos informales

No obstante, cuando se considera los proyectos de urbanización para estos barrios informales, la precariedad inicial en la ocupación y subdivisión del suelo genera grandes dificultades para respetar la trama urbana y las dimensiones reglamentarias para los anchos e parcelas como las vías públicas, hacen que resulte muy difícil lograr una subdivisión regular y/o racional de las parcelas y evitar inequidades y situaciones no deseadas por parte de los organismos encargados de la urbanización de los barrios (Alcalá, 2007).

Publicado en formato digital: Prof. Dr. Aníbal Marcelo Mignone. CARACTERIZACIÓN SOCIO-GEOGRÁFICA DE LOS ASENTAMIENTOS INFORMALES EN EL AGLOMERADO GRAN RESISTENCIA. Revista Geográfica Digital. IGUNNE. Facultad de Humanidades. UNNE. Año 12. № 24. Julio - Diciembre 2015. ISSN 1668-5180 Resistencia, Chaco.

En: http://hum.unne.edu.ar/revistas/geoweb/default.htm 
En cuanto al saneamiento de las condiciones sociales, debe señalarse que la población de los asentamientos se caracteriza por tener escasa cobertura social, condiciones precarias de salud y dificultades en el acceso al mercado laboral.
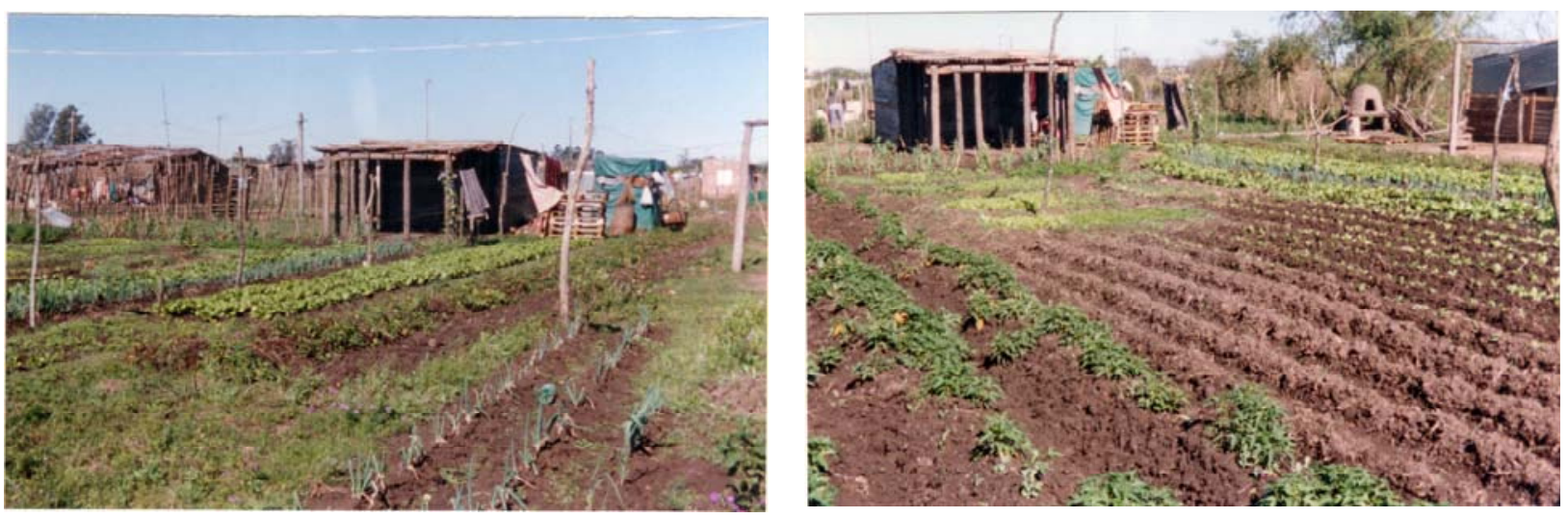

Fuente: Mignone, 2003

Imagen № 7: Huerta particular en el asentamiento Banderas Argentinas. Ciudad de Fontana. 2003

La falta de trabajo es uno de los factores condicionantes de la pobreza estructural en esta población. La manera de asistir a parte de esta población fue mediante los planes sociales, con una ayuda económica que comenzó por un breve tiempo, de 3 a 6 meses, luego de los cuales las personas retornaban a su condición de desocupados12. A principios de 2000, la asistencia se realizaba a través de los Planes Jefes y Jefas de Hogar, pero algunos habitantes de asentamientos, consideraban que era difícil la adjudicación de los mismos, porque había parejas que no tenían hijos o porque existía clientelismo político13.

El apoyo alimentario se realiza por medio de programas que intentan cubrir la dieta básica de la población. Los cuestionamientos que realizaban los asentados se refieren no sólo a la falta de cobertura para el total de la población, sino también al incremento en el número de mercaderías de la canasta emitida, dado que lo otorgado en la actualidad permite cubrir sólo unos días de la cuota alimentaria. Para solventar lo anterior, desde principios del siglo XXI, se comenzó a aplicar proyectos productivos, como el caso del Programa Prohuerta14, que permitió el desarrollo de huertas familiares o comunitarias, cuya producción se destina fundamentalmente para autoconsumo, pero los excedentes son vendidos en forma particular o a los comercios minoristas (Imagen $\mathrm{N}^{0} 7$ ).

\section{Consideraciones Finales}

Los asentamientos informales han sido una de las principales modalidades de expansión del aglomerado Gran Resistencia. En la actualidad, forman una especie de "anillo" o "cinturón periférico" que envuelve al aglomerado, especialmente por los sectores norte-noroeste, oeste y sur-suroeste. Esta forma de ocupación de los terrenos, mayormente en forma ilegal, ha ido evolucionando en cuanto a la organización y mecanismos de los grupos sociales. Hasta principios de la década de 1990 se caracterizaban por las ocupaciones "espontáneas", desorganizadas y lentas en cuanto a los reclamos de los servicios. Durante los '90 y hasta la actualidad, las tomas de terrenos son planificadas y ocupadas por grupos que tienen cierto grado de organización en la distribución y medición de las parcelas, así como en los mecanismos de gestión ante los organismos públicos. Por otra parte, las ocupaciones avanzan mayormente sobre los terrenos privados, provocando graves conflictos entre los propietarios y los ocupantes.

Los asentamientos se caracterizan por estar conformados fundamentalmente por población relocalizada, con habitantes procedentes del Gran Resistencia. Se considera importante revisar el discurso periodístico y algunas investigaciones existentes que mencionan a la migración desde el

Publicado en formato digital: Prof. Dr. Aníbal Marcelo Mignone. CARACTERIZACIÓN SOCIO-GEOGRÁFICA DE LOS ASENTAMIENTOS INFORMALES EN EL AGLOMERADO GRAN RESISTENCIA. Revista Geográfica Digital. IGUNNE. Facultad de Humanidades. UNNE. Año 12. No 24. Julio - Diciembre 2015. ISSN 1668-5180 Resistencia, Chaco.

En: http://hum.unne.edu.ar/revistas/geoweb/default.htm 
interior provincial, especialmente urbana, como causa fundamental de la formación de estos asentamientos en el Gran Resistencias; esos datos no coinciden con la realidad.

Los barrios espontáneos presentan condiciones de precariedad y resulta fundamental solucionar el servicio de agua potable y cloacas, ante el riesgo que significa la ausencia de estos dos elementos para la salud humana. Asimismo es prioritario mejorar la situación legal ante la numerosa población "enganchada" en el servicio de energía eléctrica. Los sectores no cuentan con alumbrado público, lo que acrecienta las condiciones de inseguridad.

Desde finales de la década de 1990, comienzan a implementarse los diferentes planes sociales con el objeto de paliar, en cierta medida, la falta de empleo o los bajos ingresos percibidos por los hogares pobres. Justamente, uno de los elementos claves es la falta de ingresos suficientes, así como la situación de incertidumbre en el acceso a la propiedad del terreno, lo que impide que la población realice las mejoras a las viviendas. Por otro lado, influiría el retraso en la implementación o la obtención de los planes de vivienda ante los requisitos necesarios para acceder al mismo (empleo estable, salario determinado, entre otras cosas). Por ello, una de las claves el saneamiento parcelario de los barrios, donde las adjudicaciones deben realizarse mediante planes de pagos o créditos a precios bajos y a largo plazo ante la precaria la situación económica que presenta gran parte de la población asentada. A pesar del tiempo que puede demandar el pago del terreno, es probable que sea aceptado por los habitantes a sabiendas que al saldar la deuda, tendrán su título de propiedad.

\section{NOTAS}

1. Aquí, el término de marginal se aplica de acuerdo con Margulis (1968:16) "a conjuntos de individuos situados de tal manera en el sistema, que ven restringida su participación en diversas esferas de la vida económica y social, comparados con otros grupos mayoritarios con los que están vinculados. Los grupos marginales suelen estar localizados en los límites sociales y ecológicos del sistema". En este caso en la periferia de la ciudad.

2. Los terrenos ocupados no pudieron obtenerse a través de los canales institucionales, como ser compra directa a una inmobiliaria, crédito hipotecario, etc., porque la población cuenta con escasos recursos económicos para adquirirlos.

3. Los resultados fueron obtenidos en los relevamientos realizados en los asentamientos informales del Gran Resistencia, considerando dos períodos de estudio: los asentamientos surgidos entre 1990 y 1999 en el municipio de Resistencia, y los barrios informales originados en la etapa 2000/01 en el Gran Resistencia. Ambas investigaciones fueron realizadas entre los años 2001 a 2003 mediante dos becas de las Secretaría General de Ciencia y Técnica de la UNNE.

4. Parte de sus habitantes fueron relocalizados en el barrio Jesús de Nazaret, ubicado en el sector oeste de Puerto Vilelas, en el límite con Resistencia. De cualquier manera, una nueva toma se produjo el 14 de octubre de 2007, con una instalación definitiva en el lugar.

5. En palabras de un delegado de los asentamientos, reproducida por el diario Norte, del 5/4/01:28: "Un vecino común levanta su casa en medio de la nada, gestiona el tendido de agua y luz. Llegan los negocios, empiezan a pasar las líneas de colectivos y cuando la zona se cotiza, los grandes latifundistas hacen su negocio. Es una manera de especular con el sacrificio del pobre".

6. Esta conclusión surge de haber mantenido diferentes entrevistas con los funcionarios públicos y con las propias personas residentes en los barrios informales. No obstante, se considera lo dicho por Fernandes (2008:30), que menciona que en las ciudades latinoamericanas “...con frecuencia, el precio del lote irregular es más o menos el mismo que el de la parcela regular; sin embargo, los promotores inmobiliarios son conducidos a la informalidad o "prefieren" hacer la subdivisión irregular porque es más fácil, considerando la enorme burocracia exigida. En muchas ciudades, tarda de tres a cinco años aprobar un proyecto de subdivisión, lo que hace que la "opción" por la informalidad sea cada vez más frecuente. Obviamente, todo ello tiene lugar en un contexto de falta de fiscalización y de represión, aliado a la preponderancia de sistemas políticos clientelistas que vienen fomentando y manipulando los procesos de producción informal de las ciudades".

7. Programa establecido en el ámbito nacional a partir de 1992, que busca la regularización dominial de la tenencia del suelo para la vivienda, emprendiendo la regeneración urbana a través de la implementación de proyectos que atiendan la instrumentación de servicios básicos de infraestructura

Publicado en formato digital: Prof. Dr. Aníbal Marcelo Mignone. CARACTERIZACIÓN SOCIO-GEOGRÁFICA DE LOS ASENTAMIENTOS INFORMALES EN EL AGLOMERADO GRAN RESISTENCIA. Revista Geográfica Digital. IGUNNE. Facultad de Humanidades. UNNE. Año 12. № 24. Julio - Diciembre 2015. ISSN 1668-5180 Resistencia, Chaco.

En: http://hum.unne.edu.ar/revistas/geoweb/default.htm 
y logren la solución integral del hábitat (Comisión de Tierras Fiscales Nacionales, 1994: 31). Actualmente, se denomina "Mi Pueblo".

8. El diario Norte, del 19 de enero de 2001:4 mencionaba la condición de la población instalada en el asentamiento Villa Chica: "Circula por el lugar el comentario de que muchas familias son de origen humilde y carenciadas, pero también entre el grupo ocupante, había gente que tenía sus viviendas, su trabajo y se apoderaba de esos terrenos para sus familiares".

9. En nuestro país, existe el Programa Mejoramiento de Barrios (PROMEBA) programa nacional con base federal, que se presenta como un programa social para transformar el hábitat popular. Su objetivo es mejorar la calidad de vida de la población con necesidades básicas insatisfechas, asentada en barrios con carencia de infraestructuras, problemas ambientales y/o de regularización dominial. La característica saliente de este programa es el sistema de unidades ejecutoras y direccionamiento de recursos provinciales a prioridades nacionales.

10. Muchos de los terrenos son retenidos por los propietarios para lograr su revalorización.

11. Las críticas se centran primordialmente en que el Estado provincial no tiene una política de tierras definida para los sectores más carenciados, va solucionando los conflictos a medida que se suscitan, con respuestas puntuales y coyunturales o estructuradas dentro del formato tradicional, sin asumir una lectura realista de la situación, ni formular una efectiva política de tierra y vivienda popular (Magnano, 2005).

12. Es el caso del "Plan Trabajar", programa implementado a fines de la década de los '90.

13. Recordemos que después del año 2003, los planes sociales tuvieron un incremento cuantitativo, ya que los requisitos tuvieron una menor exigencia.

14. El Prohuerta (ejecutado por el Instituto Nacional de Tecnología Agropecuaria) está destinado a mejorar las condiciones alimentarias de la población en situación de pobreza, a través de proyectos autogestionarios, llevados a cabo por los propios beneficiarios, quienes reciben capacitación para preparar huertas en las que cultivan hortalizas y verduras. En el caso de las huertas comunitarias, se desarrollan en aquellos lugares donde las condiciones ambientales no permiten el cultivo en cada parcela. Esto era factible de ver, por ejemplo, a lo largo del riacho Barranqueras.

\section{Bibliografía}

Alcalá Pallini, Laura. 2007. "Dimensiones urbanas del problema habitacional. El caso de la ciudad de Resistencia, Argentina". En: Revista INVI No 59. Volumen 22: 35 a 68. Facultad de Arquitectura y Urbanismo de la Universidad de Chile. Enero de 2007. Disponible en Internet: http://www.anuariochh.uchile.cl/index.php/INVI/article/view/8757/8559. Visitado el 10 de marzo de 2012.

Barreto, Miguel y Lorena Sánchez. 2000. "El crecimiento de las ciudades intermedias del noreste argentino en el contexto de las transformaciones regionales". En: Seminario El rol de las ciudades intermedias iberoamericanas. Facultad de Arquitectura y Urbanismo, UNNE. Versión en CD-Rom.

Barrios, Fernando. 1999. "Expansión urbana del área metropolitana del Gran Resistencia en la última década". Comunicaciones Científicas y Tecnológicas 1999. Secretaría General de Ciencia y Técnica de la Universidad Nacional del Nordeste. En Internet: www.unne.edu.ar/cyt/2000/cyt. Visitado el 05 de enero de 2008.

Bettatis, Clarisa. 2009. "Urbanización y asentamientos informales en la provincia de Buenos Aires". En: Revista Bitácora 15 (2). Universidad Nacional de Colombia, Bogotá, Colombia. P. 89-108.

Borrini, Héctor. 1998. Consideraciones acerca del proceso Geohistórico del Gran Resistencia. Revista Nordeste. Historia, No 9:97-118. 2da. Época. Serie Investigación y Ensayos. Facultad de Humanidades, UNNE. Resistencia, Chaco.

Bosch, Sonia; Gabriela Meana, Liliana Mendoza y Natalia Rodríguez. Inédito. Asentamientos espontáneos. Intervención urbana localizada en el Bario Facundo. Arquitectura V, Unidad Pedagógica C. Facultad de Arquitectura y Urbanismo, U.N.N.E., Resistencia.

Publicado en formato digital: Prof. Dr. Aníbal Marcelo Mignone. CARACTERIZACIÓN SOCIO-GEOGRÁFICA DE LOS ASENTAMIENTOS INFORMALES EN EL AGLOMERADO GRAN RESISTENCIA. Revista Geográfica Digital. IGUNNE. Facultad de Humanidades. UNNE. Año 12. No 24. Julio - Diciembre 2015. ISSN 1668-5180 Resistencia, Chaco.

En: http://hum.unne.edu.ar/revistas/geoweb/default.htm 
Comisión de Tierras Fiscales Nacionales. 1994. Marco Teórico para una Política Nacional de Tierra, Vivienda y Desarrollo Urbano-Ambiental Sustentable. Presidencia de la Nación. Programa Arraigo.

Cozzi, Carlos. S/f. Organización popular y asentamientos urbanos. Informe de Maestría (inédito). Universidad Nacional de Entre Ríos.

Fernandes, Edesio. 2008. Consideraciones generales sobre las políticas públicas de regularización de asentamientos informales en America Latina. En: Revista EURE (online). Volumen 34, No 102. Pp. 25-38, agosto 2008. Disponible en Internet: http://www.scielo.cl/scielo.php?pid=S0250-71612008000200002\&script=sci arttext Visitado el 06 de mayo de 2012.

Magnano, María C. 2005. "El suelo urbano y los asentamientos informales en el Gran Resistencia, Chaco, Argentina". En: Revista INVI No 54. Versión online. Facultad de Arquitectura y Urbanismo, Universidad de Chile. Volumen 20: 10-17. Agosto de 2005. Disponible en Internet: http://revistainvi.uchile.cl/index.php/INVI/issue/view/63. Visitado el 26 de septiembre de 2009.

Marotte, Marta. 2000. "Problemas de la expansión urbana de la ciudad de Formosa (parte II)". En: Actas XX Encuentro de Geohistoria Regional. Instituto de Investigaciones GeohistóricasConicet, Resistencia. Volumen II: 591:600.

Mignone, Aníbal. 2002. Década del '90: los asentamientos espontáneos en el crecimiento de Resistencia. XX Encuentro de Geohistoria Regional. Instituto de Investigaciones Geohistóricas-Conicet, Resistencia. Volumen II: 639-654.

Mignone, Aníbal. 2004. "La movilidad territorial desde la perspectiva de la población instalada en asentamientos espontáneos en el Gran Resistencia, a principios del siglo XXI". En: VII Jornada Argentina de Estudios de la Población (AEPA). Tafí del Valle, Tucumán, Argentina. 315-328.

Mignone, Aníbal. 2008. "Las condiciones de pobreza en las capitales del nordeste argentino a principios del siglo XXI. Su análisis a través del Índice de Privación Material de los Hogares (IPMH)". En: XXVII Encuentro de Geohistoria Regional. Instituto de Investigaciones Geohistóricas-Conicet. 28-30 de agosto de 2008. Versión en CD-Rom.

Norte. 1994. "2500 familias ocupan ilegalmente los terrenos en Resistencia". Diario Norte. 26 de noviembre de 1994. Pp. 13-14.

Norte. 1994. "2500 familias ocupan ilegalmente los terrenos en Resistencia". Diario Norte. 26 de noviembre de 1994. Pp. 13-14.

Norte. 1995. "Hay 14 mil familias usurpando terrenos". Diario Norte.19 de marzo de 1995. P.8

Norte. 2000. "Familias pobres tomaron un terreno sobre avenida Alberdi". Diario Norte. Resistencia, Chaco. 06 de Diciembre de 2000. Pág. 11.

Norte. 2001. "El gobierno y los "sin tierra" buscan solución a los asentamientos". Diario Norte. 5 de abril de 2001. P. 28.

Norte. 2001. "Nuevo informe oficial: 12.000 casos resueltos en cinco años con el Plan Tierra". Diario Norte. 23 de abril de 2001. P.4

Norte. 2001. "Vecinos ocuparon un predio municipal en Villa Chica". Diario Norte.19 de enero de 2001. P. 4.

Norte. 2002. "200 familias se asentaron frente al aeropuerto". Diario Norte. 07 de agosto de 2002. P 7.

Norte. 2002. "Nadie detiene la ocupación de tierras en Resistencia". Diario Norte. Resistencia, Chaco. Jueves 08 de agosto de 2002. P. 4.

Norte. 2008. "Filmación prueba venta ilegal de lotes en campo Zampa: hasta hay "ofertas"'. Diario Norte. 19 de enero de 2008. P. 10.

Norte. 2008. "En el Gran Resistencia, hay 100.000 pobladores que no tienen domicilio". Diario Norte. Resistencia, Chaco. 18 de marzo de 2008. P. 44.

Norte. 2009. "Vuelven las usurpaciones: 46 viviendas en el Mapic y cuatro manzanas sobre avenida Soberanía Nacional". Diario Norte. 21 de mayo de 2009. P. 7.

Publicado en formato digital: Prof. Dr. Aníbal Marcelo Mignone. CARACTERIZACIÓn SOCIO-GEOGRÁFICA DE LOS ASENTAMIENTOS INFORMALES EN EL AGLOMERADO GRAN RESISTENCIA. Revista Geográfica Digital. IGUNNE. Facultad de Humanidades. UNNE. Año 12. NN 24. Julio - Diciembre 2015. ISSN 1668-5180 Resistencia, Chaco.

En: http://hum.unne.edu.ar/revistas/geoweb/default.htm 